\title{
Relationship between stigma and health- related quality of life in patients diagnosed with HIV
}

\author{
Susana Barradas ${ }^{1}$, Carolyn Finck ${ }^{2}$ \\ ${ }^{1}$ School of Social and Human Sciences, Universidad Externado de Colombia, Bogotá, Colombia \\ ${ }^{2}$ Department of Psychology, School of Social and Human Sciences, Universidad de los Andes, Bogotá, Colombia
}

\begin{abstract}
Introduction: Human immunodeficiency virus (HIV) epidemic is one of the main problems in public health, and health-related quality of life (HRQoL) is usually negatively affected. Stigma is one of the factors related to a lower HRQoL.

Material and methods: We aimed to assess this relationship, and felt stigma was measured using HIV felt stigma scale, while HRQoL was measured with EORTC QLQ-C30. We interviewed 140 patients, and $10.9 \%$ of our respondents reported feeling severe stigma, $25.4 \%$ moderate stigma, $26.1 \%$ mild stigma, and $37.7 \%$ absence of stigma.

Results: Average score for overall HRQoL was $83.3(\mathrm{SD}=21.4)$. Higher levels of stigma were associated with lower levels of perceived global HRQoL $(\beta=-0.32, p=0.001)$. Moreover, higher levels of stigma were correlated with a lower physical function $(\beta=-0.27, p=0.005)$, role function $(\beta=-0.28$, $p=0.001)$, cognitive function $(\beta=-0.30, p=0.001)$, social function $(\beta=-0.32, p=0.001)$, and emotional function $(\beta=-0.60, p<0.001)$.
\end{abstract}

Conclusions: Reducing felt stigma could help improve HRQoL in HIV-positive patients.

HIV AIDS Rev 2021; 20, 3: 179-186 DOI: https://doi.org/10.5114/hivar.2021.108786

Key words: felt stigma, health-related quality of life, HIV, chronic disease.

\section{Introduction}

Human immunodeficiency virus (HIV) is considered a main public health concern, and it is the cause of preventable morbidity and mortality worldwide. In 2018, nearly 38 million people were living with HIV around the world, of which 36.2 million were adults and 1.7 million were newly infected children [1]. In addition, 770,000 people died from AIDS in the same year [1]. The third most affected region of the globe, after Africa and Southeast Asia, is the region of Americas, with 3.4 million people living with HIV (PLWH) [2], identifying the region as one of the most vulnerable in relation to HIV epidemic. Also, a publication by
Inter-American Development Bank in 2002 stated that HIV prevalence rates in Latin America and the Caribbean were the second fastest growing in the world (2\%), and that for risk groups, these estimations were even higher with a $5 \%$ of prevalence rate [3]. In Colombia, the statistics for 2017 showed that 150,000 people were HIV-positive and 4.400 thousand people died from AIDS in the same year [3].

The HIV epidemic represents an important barrier to the human, economic, and social development of our societies [4]. However, thanks to the evolution of antiretroviral therapies (ART), a large number of patients have been able to improve their prognosis and years of life without morbidity [5]. The last aspect becomes important in quality of life 
(QoL) and well-being of patients since both can be affected by the presence of diagnosis [6]. Also, it is worth noting that these patients need integral care in addition to biomedical care, and in order to optimize this care, it is necessary to better understand which factors can contribute to a better psychological well-being and QoL [7].

\section{Stigma in people living with HIV}

Several studies have mentioned that stigma is one of the main barriers to eradicate HIV virus. In this sense, it represents a barrier for people with HIV to access healthcare [8], and make positive decisions regarding their health and life in general [9]. Also, it promotes further discrimination and inhibits disclosure of HIV status to others, particularly sexual partners [10]. In this context, stigma has been described as the process, in which a person experiences "feelings of fear and shame stemming from real, potential, or imaginary attitudes, or discriminatory acts directed toward an HIV-positive individual and engendered by that individual's HIV status" (p. 2) [11]. Tsai et al. [12] theorized that one of the drivers related to stigma reproduction is its association with disability, economic incapacity, and death, at least in contexts of poverty, such as sub-Saharan Africa. Another idea that reproduces stigma is its association with marginalized groups because of their sexual behavior, like men who have sex with men (MSM), or other behavior, including drug injections amongst drug users [12]. Regarding stigma mechanisms, three types of mechanisms have been identified. Firstly, an enacted stigma is the result of previous negative discrimination experiences regarding HIV status [10]. Secondly, an anticipated stigma relates to the expected adverse opinions and behaviors of others [10]. The third mechanism is an internalized stigma, which refers to self-stigmatizing beliefs of PLWH [10].

Studies have reported that PLWH frequently experience stigma related to their health diagnosis [13], which represents negative effects for their health outcomes [13] and affects basic psychological processes, including long-term cognition, emotion, and behavior [10, 13].

\section{Stigma and quality of life}

HRQoL can be defined as "how well a person functions in their life and his or her perceived well-being in physical, mental, and social domains of health" (p. 241) [14]. Although, PLWH can have a life expectation similar to that of general population [15], a research also shows a decrease in their QoL, specifically poor mental QoL [16]. Poor mental QoL is reported in individuals experiencing other chronic diseases, such as diabetes mellitus types 1 and 2, in which PLWH show the poorest results [16].

The stigma felt by PLWH has an impact on their physical and psychological well-being, and it is associated with lower levels of HRQoL [17]. A recent meta-analysis including 64 studies found that HIV-related stigma was associated with higher rates of depression and lower social support in PLWH [18]. Also, the study found relationships between HIV-related stigma and emotional and mental distress [18]. The majority of studies revised were interested in associations between these two constructs, and the studies mainly focused on stigma as a predictor of QoL in PLWH. Moreover, stigma has also been studied as a mediator of relationship between other psycho-social and medical variables and QoL. One example is a study by Li et al. [19], who aimed to evaluate the role of stigma as a mediator variable between self-efficacy and medication adherence, and QoL in PLWH. Results showed a partial mediation in the first relationship explored, and a totally mediated path, through stigma, between self-efficacy and QoL [19].

To date, research on stigma in patients with HIV in Colombia has been more oriented towards stigma and discrimination in health professionals, and its influence on patients' access to health services $[20,21]$. Moreover, a recent study for HIV/AIDS bibliography analysis showed that between 1991 and 2017, in Colombia there were only 6 studies regarding stigma and PLWH (in comparison with the United States, 406 publications in the same period) [22], which emphasize the importance of addressing these aspects in PLWH. To our knowledge, there are no studies assessing the relationship between stigma and QoL of PLWH in Colombia. Therefore, the aim of the present study was to address both stigma and perception of HRQoL in a sample of participants diagnosed with HIV. Additionally, we wanted to explore the relationship between stigma and the perception of HRQoL in this population.

\section{Material and methods}

\section{Study design and inclusion criteria}

This study used a cross-sectional design with a convenience sample, and was neither randomized nor stratified. Data was obtained between July 2018 and August 2019. The inclusion criteria were to be an adult (18 years or older) diagnosed with HIV, managed as an outpatient, who was living in the city of Bogota, and who agreed to participate in the study after reading and signing an informed consent form. Exclusion criteria were to have any cognitive, neurological, or psychiatric impairment, and to be in a more severe stage of the disease (i.e., AIDS). We focused on the city of Bogota because it is one of the cities with the highest average prevalence of HIV in the country (e.g., a prevalence rate of $16.3 \%$ between MSM) [23].

\section{Participants}

The final sample included 140 adults, who participated in a larger study on psycho-social factors related to HIV diagnosis. Participants were HIV-positive and received assistance for their diagnosis in the city of Bogota. Patients were recruited through healthcare programs for people with HIV in two places: 1. A health clinic (Hemera Unidad de Infec- 
tología IPS SAS), 2. A community-based healthcare organization (Corporación Red Somos). Eligible patients were informed about the study by administrative staff that receives patients for consultations, and, if they agreed, to participate in the study. They were contacted with one of interviewers of the project, who gave them a questionnaire inside an envelope to guarantee the confidentiality of data. A written informed consent was obtained from all participants. If patients asked for help in completing the questionnaires, faceto-face interviews were performed.

The present study was approved by ethics committee of the Universidad Externado de Colombia (act number 8 of 2018).

\section{Instruments}

Four interviewers worked on the project and received prior training in regard to the project implementation and application of instruments in the questionnaire. The questionnaire was composed of a socio-demographic section as well as different scales measuring psycho-social variables.

\section{Felt stigma instrument}

To address felt stigma, HIV felt stigma scale (HFSS) [24] composed of 17 items with answers on a 4-point Likert scale, ranging from "never" to "always", was used. The scale measures four dimensions of stigma, including personalized stigma (items 1 to 5), disclosure concerns (items 6 to 9), negative self-image (items 10 to 14), and concern with public attitudes (items 15 to 17). Total score was obtained by adding answers of each item, with a higher total score meaning higher levels of felt stigma. The original scale showed good reliability values for the total scale $(\alpha=0.91)$ [24]. Additionally, good reliability values were found for sub-scales, including personalized stigma ( $\alpha=0.88)$, disclosure concerns $(\alpha=0.85)$, negative self-image $(\alpha=0.77)$, and concern with public attitudes $(\alpha=0.80)$ [24]. In the present sample, results also showed good reliability indices for the total scale $(\alpha=0.89)$ and sub-scales (Cronbach's $\alpha$ ranging between 0.70 and 0.81$)$.

\section{Health-related quality of life instrument}

To measure HRQoL, EORTC QLQ-30 questionnaire was used. This scale includes a 30-item Likert scale of 4 points ranging from "not at all" to "very much". EORTC QLQ-30 sub-scales consist of the following: physical, cognitive, role, and emotional and social functioning. Also, the instrument contains a two-item global health/QoL scale. The higher the score obtained in all sub-scales and in the global scale, the better the quality of life (QoL) perceived by the respondent [25]. This scale has been used in different populations with chronic disease, such as cancer [26] or HIV [27], and in general population. A study with general population of Colombia showed good internal consistency for all the sub-scales and global scale ( $\alpha$ ranging between 0.65 and 0.88) [26].
Table 1. Socio-demographic data

\begin{tabular}{|c|c|}
\hline Variables & $\mathrm{M}$ or $\%$ \\
\hline \multicolumn{2}{|l|}{ Sex } \\
\hline Men & $74.6 \%$ \\
\hline Women & $25.4 \%$ \\
\hline \multicolumn{2}{|l|}{ Gender } \\
\hline Male & $72.7 \%$ \\
\hline Female & $23.7 \%$ \\
\hline Transgender & $3.6 \%$ \\
\hline \multicolumn{2}{|l|}{ Sexual orientation } \\
\hline Heterosexual & $47.8 \%$ \\
\hline Homosexual & $44.9 \%$ \\
\hline Bisexual & $5.1 \%$ \\
\hline Other & $2.2 \%$ \\
\hline Mean age & $58(S D=6.5)$ \\
\hline \multicolumn{2}{|l|}{ Marital status } \\
\hline Single & $61.4 \%$ \\
\hline Cohabiting & $20.7 \%$ \\
\hline Married & $5.7 \%$ \\
\hline Widowed & $2.1 \%$ \\
\hline \multicolumn{2}{|l|}{ Education } \\
\hline Elementary school & $23.3 \%$ \\
\hline High school & $22.5 \%$ \\
\hline $\begin{array}{l}\text { Elementary school incomplete or no } \\
\text { studies }\end{array}$ & $18.6 \%$ \\
\hline Technical or technological studies & $15.1 \%$ \\
\hline University degree & $14.3 \%$ \\
\hline Postgraduate degree & $6.2 \%$ \\
\hline \multicolumn{2}{|l|}{ Employment status } \\
\hline Student & $20.9 \%$ \\
\hline Retired & $20.2 \%$ \\
\hline Housekeeper & $18.6 \%$ \\
\hline Employee and student & $18.6 \%$ \\
\hline Independent worker & $14.0 \%$ \\
\hline Employed & $3.5 \%$ \\
\hline Unemployed & $1.6 \%$ \\
\hline
\end{tabular}

\section{Statistical analysis}

At first, a descriptive analysis was performed with demographic data. HRQoL global score and sub-scales' scores were calculated using formulas provided in EORTC scoring manual [29]. In this sense, we firstly calculated raw score for all scales using the following formula: Raw score $=\left(\mathrm{I}_{1}+\mathrm{I}_{2}+\ldots\right.$ $\left.+I_{n}\right) / n$. Subsequently, we analyzed functional scales, symptom scales, and global health status according to scoring instructions in the manual [29]. All dimensions were transformed into a 0 to 100 scale according to scoring instructions [29]. 
Table 2. Mean scores and SD of scales separated by sex $(n=140)$

\begin{tabular}{|c|c|c|c|}
\hline Factor & Total & Females & Males \\
\hline Time since diagnosis (months) & $85.0(72.1)$ & $75.4(57.7)$ & $86.4(74.2)$ \\
\hline Felt stigma (total score) & $20.3(12.1)$ & $19.6(13.2)$ & $20.2(11.7)$ \\
\hline \multicolumn{4}{|l|}{ HRQoL } \\
\hline Global health/HRQoL & $83.3(21.4)$ & $86.9(22.8)$ & $82.9(20.0)$ \\
\hline Physical functioning & $94.3(14.5)$ & $93.7(19.1)$ & $95.2(11.4)$ \\
\hline Role functioning & $90.6(22.0)$ & $91.4(23.3)$ & $91.2(19.9)$ \\
\hline Cognitive functioning & $86.6(20.2)$ & $92.3(14.2)$ & $85.2(21.1)$ \\
\hline Social functioning & $87.1(21.4)$ & $90.9(23.2)$ & $85.9(24.3)$ \\
\hline Emotional functioning & $79.1(24.4)$ & $82.1(24.0)$ & $78.0(24.8)$ \\
\hline
\end{tabular}

HRQOL - health-related quality of life

Table 3. Frequency of felt stigma categories $(n=140)$

\begin{tabular}{l|c|c|c|c}
\hline Factor & $\begin{array}{c}\text { No stigma } \\
(\%)\end{array}$ & $\begin{array}{c}\text { Mild stigma } \\
(\%)\end{array}$ & $\begin{array}{c}\text { Moderate stigma } \\
(\%)\end{array}$ & $\begin{array}{c}\text { Severe stigma } \\
(\%)\end{array}$ \\
\hline HIV felt stigma scale total & 37.7 & 26.1 & 25.4 & 10.9 \\
\hline Personalized stigma & 51.4 & 10.0 & 8.6 & 30.0 \\
\hline Disclosure concerns & 14.3 & 18.6 & 22.1 & 45.0 \\
\hline Negative self-image & 83.2 & 7.3 & 4.4 & 5.1 \\
\hline Concerns with public attitudes & 24.3 & 29.4 & 27.9 & 18.4 \\
\hline
\end{tabular}

Table 4. Correlations between felt stigma and health-related quality of life (HRQoL) $(n=140)$

\begin{tabular}{l|c}
\hline EORTC QLQ-30 & Felt stigma \\
\hline Global health/HRQoL & $-0.36^{* * *}$ \\
\hline Physical function & $-0.23^{\star *}$ \\
\hline Role function & $-0.25^{* *}$ \\
\hline Cognitive function & $-0.30^{* * *}$ \\
\hline Social function & $-0.22^{\star *}$ \\
\hline Emotional function & $-0.53^{* * *}$ \\
\hline${ }^{* *} p<0.01,{ }^{* * *} p<0.001$ &
\end{tabular}

Next, Pearson' correlation analysis was performed to identify co-variance of stigma, global HRQoL, and HRQoL functioning variables. Then, regression analyses were conducted to test different models, in which the result variable was either global HRQoL or specific function sub-scales of EORTC QLQ-30. Independent variables in these models were felt stigma (total scale and categorical variables), socio-economic level, and sex and age. Dependent variables were either global HRQoL or specific function sub-scales of EORTC QLQ-30, depending on a model (Tables 4 and 5). We established sample size using Green's rule of thumb [30] to test the entire model with the following formula: $n=50+8^{*}$ predictors. Values of $p<0.05$ were considered statistically significant, and IBM SPSS Statistics, version 21.0 was used for the analyses.

\section{Results}

\section{Characterization of the sample}

In total, more men (105) than women (35) completed the questionnaire. Most respondents were single (61.4\%), cohabiting (20.7\%), or divorced/separated (10\%). Only a small proportion were married (5.7\%) or widowed (2.1\%). $31.2 \%$ of our respondents were employed or freelancers, $23.9 \%$ were unemployed looking for a job, $9.4 \%$ were informal workers, 6.5\% were students, and 3.6\% were housewives. Also, 19.3\% responded "other" to their current occupation situation. $35 \%$ of the respondents had a high school diploma, $23.6 \%$ presented a technical or technological degree, $19.3 \%$ had a primary school degree, $7.9 \%$ had a university degree, $6.4 \%$ were currently studying at a university or had an incomplete university degree, and $2.9 \%$ reported not having any studies. Concerning socio-economic level, $45.2 \%$ of the participants reported to have low income (strata 1 and 2), 51.1\% had middle (strata 3 and 4 ), and only $3.6 \%$ high income (strata 5), according to the income stratification in Colombia. Additionally, 100\% of the participants were taking antiretroviral therapy. Further demographic data is presented in Table 1.

The mean score for felt stigma was $20.3(\mathrm{SD}=12.1)$ on a 0 to 51 scale. Concerning HRQoL, the mean score for global function was $83.3(\mathrm{SD}=21.4)$ on a 0 to 100 scale, indicating a good general HRQoL. Regarding the EORTC sub-scales, the results showed good mean scores as well (Table 1). In Table 3, the frequency of felt stigma category scores can be found. 
Table 5. Regression model with global health-related quality of life (HRQoL) levels and sub-scales

\begin{tabular}{|c|c|c|c|c|c|c|c|c|c|}
\hline \multirow{2}{*}{$\begin{array}{l}\text { Predictive } \\
\text { variables }\end{array}$} & \multicolumn{3}{|c|}{ Model 1: Global } & \multicolumn{3}{|c|}{ Model 2: Physical } & \multicolumn{3}{|c|}{ Model 3: Role } \\
\hline & B & SE & $\beta$ & B & SE & $\beta$ & B & SE & $\beta$ \\
\hline Felt stigma & -0.55 & $-0.16^{\star *}$ & -0.32 & -0.34 & $-0.12^{\star *}$ & -0.27 & -0.51 & $0.17^{* *}$ & -0.28 \\
\hline SES & -0.02 & 1.64 & 0 & 1.39 & 1.26 & 0.10 & 0.69 & 1.80 & 0.03 \\
\hline Sex & 2.57 & 4.39 & 0.05 & -1.08 & 3.62 & -0.03 & 2.7 & 4.8 & 0.05 \\
\hline Age & 0.05 & 0.15 & 0.03 & -0.17 & 0.12 & -0.14 & -0.24 & 0.16 & -0.14 \\
\hline$R^{2}$ Nagelkerke & \multicolumn{3}{|c|}{0.13} & \multicolumn{3}{|c|}{0.11} & \multicolumn{3}{|c|}{0.10} \\
\hline $\mathrm{F}$ & \multicolumn{3}{|c|}{$3.10^{* *}$} & \multicolumn{3}{|c|}{$2.17^{\star *}$} & \multicolumn{3}{|c|}{$2.06^{*}$} \\
\hline \multirow{2}{*}{$\begin{array}{l}\text { Predictive } \\
\text { variables }\end{array}$} & \multicolumn{3}{|c|}{ Model 4: Cognitive } & \multicolumn{3}{|c|}{ Model 5: Social } & \multicolumn{3}{|c|}{ Model 6: Emotional } \\
\hline & B & SE & $\boldsymbol{\beta}$ & B & SE & $\boldsymbol{\beta}$ & B & SE & $\beta$ \\
\hline Felt stigma & -0.50 & $-0.15^{\star *}$ & -0.30 & -0.63 & $-0.187^{\star *}$ & -0.32 & -1.19 & $0.15^{\star * *}$ & -0.60 \\
\hline SES & 0.45 & 1.59 & 0.02 & -3.67 & 1.95 & -0.18 & -0.47 & 1.64 & -0.02 \\
\hline Sex & 8.28 & $4.25^{\star}$ & 0.18 & -0.03 & 5.61 & 0 & 4.37 & 4.39 & 0.07 \\
\hline Age & -0.26 & 0.14 & -0.16 & 0.11 & 0.19 & -0.06 & -0.06 & 0.15 & -0.03 \\
\hline$R^{2}$ Nagelkerke & \multicolumn{3}{|c|}{0.12} & \multicolumn{3}{|c|}{0.15} & \multicolumn{3}{|c|}{0.36} \\
\hline $\mathrm{F}$ & \multicolumn{3}{|c|}{$3.88^{\star \star}$} & \multicolumn{3}{|c|}{$2.98^{\star *}$} & \multicolumn{3}{|c|}{$14.75^{* * *}$} \\
\hline
\end{tabular}

SES - socio-economical level; $B$ - unstandardized beta; $\beta$ - standardized beta

Regarding the frequency of different stigma categories of the applied scale, more than $60 \%$ of the sample felt at least mild stigma. Only $37.7 \%$ reported feeling "no stigma", while mild and moderate stigma were the most frequent categories (26.1\% and $25.4 \%$, respectively). Severe stigma was reported by only $10 \%$ of the interviewed participants. Also, $30 \%$ of the participants feels severe personalized stig$\mathrm{ma}$, and $45 \%$ reported severe disclosure concerns. To understand the relationship between felt stigma and HRQoL scales, correlation analyses were performed. Results are shown in Table 4.

As demonstrated in Table 3, sall HRQoL scales were negatively correlated with the global score of felt stigma scale, and these relations were also statistically significant $(p<0.01)$. The higher the stigma felt by respondents, the lower their perception of HRQoL in every domain assessed by the scale.

In order to explain participants' levels, additional regression analyses were performed. In Table 5, the results of these analyses are presented.

Table 5 demonstrates the relationship between predictor variables, the global scale, and sub-scales of HRQoL. A negative and significant association was found between felt stigma and global HRQoL, in which higher levels of felt stigma were associated with lower levels of perceived global HRQoL of the participants $(\beta=-0.32, p=0.001)$. The same tendency in the results was found for the following subscales: physical function $(\beta=-0.27, p=0.005)$, role function $(\beta=-0.28, p=0.001)$, cognitive function $(\beta=-0.30$, $p=0.001)$, social function $(\beta=-0.32, p=0.001)$, and emotional function $(\beta=-0.60, p<0.001)$. For these subscales, the higher the stigma felt by the individual, the lower the perceived levels of HRQoL. The variance explained by each of the tested models differed, and the model that showed a greater explained variance $(36 \%)$ was model 6 that included emotional function as a dependent variable $(\mathrm{R}=0.60, \mathrm{~F}(4.105)=14.75, p<0.001)$.

No statistically significant association was found between covariates and HRQoL, except for model 4 (cognitive HRQoL). In this case, being a woman was associated with better cognitive function, as presented in Table 5 .

Table 6 shows the relationship between predictor variables, including stigma sub-scales and HRQoL. A negative and significant association was found between personalized stigma and global HRQoL, in which higher levels of personalized stigma were associated with lower levels of perceived global HRQoL of the participants $(\beta=-4.41$, $p=0.009)$. We found similar results in the effects of personalized stigma for the following sub-scales: physical function $(\beta=-4.31, p=0.001)$, role function $(\beta=-5.03$, $p=0.006)$, social function $(\beta=-4.09, p=0.003)$, and emotional function $(\beta=-4.85, p=0.004)$. For these sub-scales, the higher the personalized stigma, the lower the perceived levels of HRQoL.

Furthermore, we found significant association between negative self-image and HRQoL. In this case, a higher negative self-image was related to lower levels of HRQoL, both for global HRQoL $(\beta=-7.95, p=0.009)$ and for the following sub-scales: role function $(\beta=-8.94, p=0.001)$, cognitive function $(\beta=-9.29, p=0.000)$, and emotional function $(\beta=-14.17, p=0.000)$.

\section{Discussion}

In the present sample, a predominance of men (104) was found compared with women (35). Regarding this, 
Table 6. Regression model with categorical stigma variable with global HRQoL levels and sub-scales

\begin{tabular}{|c|c|c|c|c|c|c|c|c|c|}
\hline \multirow[t]{2}{*}{ Predictive variables } & \multicolumn{3}{|c|}{ Model 1: Global } & \multicolumn{3}{|c|}{ Model 2: Physical } & \multicolumn{3}{|c|}{ Model 3: Role } \\
\hline & B & SE & $\beta$ & B & SE & $\beta$ & B & SE & $\boldsymbol{\beta}$ \\
\hline Personalized stigma & -4.41 & $1.66^{\star *}$ & -0.28 & -4.31 & $1.24^{\star \star}$ & -0.38 & -5.03 & $1.78^{\star \star}$ & -.30 \\
\hline Disclosure concerns & 0.12 & 1.83 & 0 & -0.29 & 1.37 & -0.02 & 0.51 & 1.96 & .02 \\
\hline Negative self-image & -7.95 & $2.52^{\star *}$ & -0.30 & -1.35 & 1.89 & -0.07 & -8.94 & $2.71^{\star *}$ & -.31 \\
\hline Concerns with public attitudes & 1.75 & 1.97 & 0.08 & 2.43 & 1.47 & 0.16 & 3.56 & 2.11 & .16 \\
\hline SES & -0.03 & 1.58 & 0 & -0.94 & 1.18 & 0.07 & 0.51 & 1.70 & .02 \\
\hline Sex & 1.72 & 4.24 & 0.03 & -0.34 & 3.17 & -0.01 & 1.86 & 4.55 & .03 \\
\hline Age & 0.05 & 0.14 & 0.03 & -0.18 & 0.11 & -0.15 & -0.23 & 0.15 & -.13 \\
\hline$R^{2}$ Nagelkerke & \multicolumn{3}{|c|}{0.21} & \multicolumn{3}{|c|}{0.18} & \multicolumn{3}{|c|}{0.22} \\
\hline $\mathrm{F}$ & \multicolumn{3}{|c|}{$3.94^{* *}$} & \multicolumn{3}{|c|}{$3.20^{\star *}$} & \multicolumn{3}{|c|}{$4.23^{* \star *}$} \\
\hline \multirow[t]{2}{*}{ Predictive variables } & \multicolumn{3}{|c|}{ Model 4: Cognitive } & \multicolumn{3}{|c|}{ Model 5: Social } & \multicolumn{3}{|c|}{ Model 6: Emotional } \\
\hline & B & SE & $\beta$ & B & SE & $\beta$ & B & SE & $\beta$ \\
\hline Personalized stigma & -2.14 & 1.62 & -0.14 & -4.09 & $1.89^{*}$ & -0.22 & -4.85 & $1.65^{\star \star}$ & -0.26 \\
\hline Disclosure concerns & -0.28 & 1.79 & -0.01 & 2.61 & 2.08 & 0.12 & -3.38 & 1.82 & -0.15 \\
\hline Negative self-image & -9.29 & $2.47^{\star \star \star}$ & -0.36 & -9.51 & 2.87 & -0.31 & -14.17 & $2.51^{\star \star \star}$ & -0.45 \\
\hline Concerns with public attitudes & 0.98 & 1.92 & 0.05 & -1.44 & 2.24 & -0.06 & 0.27 & 1.96 & 0.01 \\
\hline SES & 0.53 & 1.55 & 0.03 & -3.74 & 1.80 & -0.18 & -0.22 & 1.57 & -0.01 \\
\hline Sex & 7.68 & 4.15 & 0.16 & 0.75 & 4.83 & 0.01 & 3.72 & 4.22 & 0.06 \\
\hline Age & -0.27 & $0.14^{*}$ & -0.17 & 0.21 & 0.16 & -0.11 & -0.07 & 0.14 & -0.04 \\
\hline$R^{2}$ Nagelkerke & \multicolumn{3}{|c|}{0.21} & \multicolumn{3}{|c|}{0.23} & \multicolumn{3}{|c|}{0.43} \\
\hline $\mathrm{F}$ & \multicolumn{3}{|c|}{$3.95^{\star *}$} & \multicolumn{3}{|c|}{$4.58^{\star \star *}$} & \multicolumn{3}{|c|}{$11.36^{\text {***}}$} \\
\hline
\end{tabular}

SES - socio-economical level, $B$ - unstandardized beta, $\beta$ - standardized beta.

HIV estimates for Colombia (in adults aged 15 to 49 years) showed a higher prevalence rate in men $0.7(0.5-0.8)$ compared with women 0.2 (0.1-0.2) [28]. Evidence in the United States shows that, by risk group, gay, bisexual, and men who have sex with men (MSM), have a higher prevalence of HIV infection [32], and the increased risk of acquiring HIV amongst key populations, such as MSM, is 22 times higher compared with non-vulnerable groups [1], largely because of stigma and discrimination that lead to high-risk behavior. Regarding high-risk behavior in Colombia, evidence shows that MSM are the second risk group (after transgendered people with a prevalence of $21.4 \%$ ), with the highest prevalence (17\%) of HIV infection [28].

In our study, descriptive results showed good average levels of global HRQoL (a score of 83.3). Also, results for HRQoL sub-scales showed good average scores (between 79.1 and 94.3). The lowest score found for sub-scales was for emotional function. Normative values in the general population in Colombia that used the same scale showed average scores of global HRQoL of 77.1 [26]. For sub-scales, normative values indicated scores between 87.6 and 92.7. Also, normative values in the general population demonstrated that, between sub-scales, the lower score found was for emotional function sub-scale [26]. Although our results showed a higher score for the global and physical functions HRQoL, in comparison with Colombian normative values, for the rest of sub-scales, the scores were lower. These paradoxical findings regarding HRQoL scores in the present study may be a result of consistent use and good adherence to antiretroviral therapy. Considering that all participants in this study were on antiretroviral drugs, this could be one of the explanations for high mean scores of HRQoL. Also, our findings support other results previously reported in the literature showing good HRQoL indices in PLWH $[33,34]$. Furthermore, these results are particularly interesting since they can reveal the presence of a response shift, which has been observed in studies on QoL [35]. This response has been described as "a change in the meaning in one's self-evaluation of a target construct" (p. 1,508) [36], as a result of adaptation process to chronic disease, which could also help to explain HRQoL values found in the present study.

Regarding felt stigma, the mean scores were below median, which can be seen as low perceived stigma in the sample in general. However, distribution of felt stigma by categories indicated that more that $60 \%$ of the sample perceived some level of stigma, of which, $10 \%$ of the respondents perceived severe stigma. These results are similar to that of other studies on stigma felt by PLWH. In a study from Puerto Rico, $80 \%$ of participants showed some level of stigma [11], and in a Finnish study, $45.7 \%$ of subjects reported moderate to se- 
vere forms of self-stigma [17]. In the present study, we found that a large proportion of the participants reported feeling severe personalized stigma (30\%) and severe disclosure concerns (45\%). Similar results have been found in other studies with PLWH [36, 37].

HIV-related stigma was associated with a lower HRQoL. Results showed that the higher the stigma felt by the patients, the lower their perception of HRQoL, both for global scale and for other sub-scales. Our results support the findings of those reported in the literature. For example, one study that investigated the relationship between perceived stigma, QoL, and suicidal ideation amongst PLWH, observed that the higher the stigma perceived in these patients, the lower the QoL level perceived, and therefore, a higher presence of suicidal ideation [38]. Moreover, another study found that stigma perceived by PLWH was negatively correlated with QoL, particularly in these four domains: physical, psychological, social, and environmental [39]. Here, we found that the presence of personalized stigma and negative self-image adversely contributed to a global perception of HRQoL and specific sub-scales. A study that aimed to investigate the relationship between stigma and QoL in PLWH found similar results; participants with personalized stigma and negative self-image were between 2 and 3.4 times more at risk of severe depression, and symptoms of depression were inversely associated with QoL [40].

In our sample, women reported to have better cognitive function compared with men (model 4 tested). Our results support previous findings reported in the literature, showing a better cognitive and neuro-cognitive function in women living with HIV comparing with their male counterparts $[38,39,41]$.

The present study used a cross-sectional design, which is a limitation. Therefore, a longitudinal perspective or repeated measures should be considered in future studies, particularly including patients' viral load, time receiving TAR, and cause of the infection (perinatal or behavioral). Moreover, we could have a self-selection bias from the part of study subjects, meaning that in our sample, we could have the most motivated individuals that wanted and agreed to take part in the study.

Also, future analyses could consider the variation of interest variables by socio-demographic characteristics, including sex, age groups, and sexual orientation. Finally, we did not take into account a possible intersection of HIV-related stigma and other forms of stigmatization (e.g., homophobia, gender discrimination, etc.) that could increase the level of stigma felt by HIV-positive individuals.

\section{Conclusions}

The aim of this study was to explore the relationship between felt stigma and HRQoL, and to describe the levels of HRQoL and felt stigma in patients with HIV. The results demonstrated good levels of HRQoL for the global scale and all of the sub-scales. Furthermore, in our sample, more than $60 \%$ of the participants reported feeling some level of stig- ma, and it is particularly worrying that $10 \%$ of the subjects reported perceiving severe stigma.

In our study, felt stigma was negatively associated with HRQoL, where higher levels of felt stigma predicted lower QoL for both the global scale and the measured sub-scales.

\section{Acknowledgements}

This work was supported by the School of Social and Human Sciences at the Universidad Externado de Colombia.

The authors thank the School of Social and Human Sciences at the Universidad Externado de Colombia for supporting this work. Also, the authors acknowledge José Guillén, Miguel Barriga, and John Ramírez at Corporación Red Somos, and Dr. Henry Mendoza at Hemera Unidad de Infectologia IPS for supporting this study by facilitating contact with their patients. We also wish to acknowledge Christine Gregory and Andreas Hinz for their comments on earlier versions of this manuscript.

\section{Conflict of interest}

The authors have no conflict of interest.

\section{References}

1. The United Nations Joint Programme of HIV/AIDS (UNAIDS). Fact sheet - Global AIDS update 2019. Geneva: UNAIDS, 2018. Available from: https://www.unaids.org/sites/default/files/media_ asset/UNAIDS_FactSheet_en.pdf.

2. The United Nations Joint Programme of HIV/AIDS (UNAIDS). Report on the global HIV/AIDS epidemic. Geneva: UNAIDS 2018. Available from: https://www.unaids.org/sites/default/files/media_ asset/unaids-data-2018_en.pdf.

3. Aggleton P, Parker R, Maluwa M. Stigma, discrimination and HIV/ AIDS in Latin America and the Caribbean. Washington, InterAmerican Development Bank; 2002.

4.Estrada-MontoyaJH,Escobar-LeguízamoDN,Briceño-CastellanosJF. Educación de pares como estrategia de prevención de la infección por VIH en adolescentes: referentes teóricos y metodológicos. Revista de Gerencia Política en Salud 2011; 10: 46-66.

5. Oguntibeju OO. Quality of life of people living with HIV and AIDS and antiretroviral therapy. HIV AIDS 2012; 4: 117-124.

6. Passos S, Souza LD. An evaluation of quality of life and its determinants among people living with HIV/AIDS from Southern Brazil. Cad Saúde Pública 2015; 31: 800-814.

7. Enimil A, Nugent N, Amoah C, Norman B, Antwi S, Ocran J, et al. Quality of life among Ghanaian adolescents living with perinatally acquired HIV: a mixed methods study. AIDS Care 2016; 28: 460-464.

8. Global Network of People Living with HIV (GNP+). The People Living with HIV Stigma Index 2015. Available from: http://www. stigmaindex.org/.

9. NAPWA SA. HIV Leadership through Accountability Programme: GNP+, NAPWA SA. PLHIV Stigma Index OR Tambo Region Assessment, Germiston, NAPWA SA. 2012 Available from: https:// www.gnpplus.net/assets/wbb_file_updown/2118/Stigma\%20 index\%20-\%20South\%20Africa.pdf.

10. Kalichman SC. The harms of internalized AIDS Stigma: a comment on Tsai et al. Ann Behav Med 2013; 46: 256-257.

11. Jiménez JC, Morales M, Castro E, Puig M, Vélez CN, Santiago L, et al.. Levels of Felt Stigma among a Group of People with HIV in Puerto Rico. Puerto Rico Health Sciences Journal 2012; 31: 64-70. 
12. Tsai A, Bangsberg DR, Weisser SD. Harnessing poverty alleviation to reduce the stigma of HIV in sub-Saharan Africa. PLoS Med 2013; 10: e1001557.

13. Turan B, Budhwani H, Fazeli PL, et al. How does stigma affect people living with HIV? The mediating roles of internalized and anticipated HIV Stigma in the effects of perceived community stigma on health and psychosocial outcomes. AIDS Behav 2017; 21: 283-291.

14. Hays RD, Reeve BB. Measurement and modeling of health-related quality of life. In: Heggenhougen K, Quah S (eds.). International Encyclopedia of Public Health, 241-252. San Diego: Academic Press; 2008.

15. Pozniak A. Quality of life in chronic HIV infection. Lancet 2014; 1: 6-7.

16. Engelhard E, Collete S, van Dijk P, et al. Health-related quality of life of people with HIV: an assessment of patient related factors and comparison with other chronic diseases. AIDS 2018; 32: 103-112.

17. Nobre N, Pereira M, Roine RP, Sutinen J, Sintonen H. HIV-related self-stigma and health-related quality of life of people living with HIV in Finland. J Assoc Nurses AIDS Care 2017; 29: 254-265.

18. Rueda S, Mitra S, Chen S, et al. Examining the associations between HIV-related stigma and health outcomes in people living with HIV/AIDS: a series of meta-analyses. BMJ Open 2016; 6: e011453.

19. Li X, Huang L, Fennie K, Williams A. Stigma mediates the relationship between self-efficacy, medication adherence, and quality of life among people living with HIV/AIDS in China. AIDS Patient Care STDS 2011; 25: 665-671.

20. Bermúdez-Román V, Bran-Piedrahita L, Palacios-Moya L, PosadaZapata IC. Influencia del estigma en torno al VIH en el acceso a los servicios de salud. Salud Pública Mex 2015; 57: 252-259.

21. Tamayo-Zuluaga B, Macías-Gil Y, Cabera-Orrego R, Henao-Peláez J, Cardona-Arias J. Estigma social en la atención de personas con $\mathrm{VIH} /$ sida por estudiantes y profesionales de las áreas de la salud, Medellín, Colombia. Rev Cienc. de la Salud 2015; 13: 9-23.

22. Tran BX, Phan HT, Latkin CA, et al. Understanding Global HIV Stigma and Discrimination: Are Contextual Factors Sufficiently Studied? (GAPRESEARCH). Int J Environ Res Public Health 2019; 16: 1899 .

23. Rubio Mendoza ML, Jacobson JO, Morales-Miranda S, Sierra Alarcón CA, Luque Núñez R. High HIV burden in men who have sex with men across Colombia's largest cities: findings from an integrated biological and behavioral surveillance study. PLoS One 2015; 10: e0131040.

24. Jiménez JC, Puig M, Ramos JC, et al. Measuring HIV felt stigma: a culturally adapted scale targeting PLWHA in Puerto Rico. AIDS Care 2010; 22: 1314-1322.

25. Aaronson NK, Ahmedzai S, Bergman B, et al. The European-Organization for Research and Treatment of Cancer QLQ-C 30. A qualityof-life instrument for use in international clinical trials in oncology. J Natl Cancer Inst 1993; 85: 365-376.

26. Finck C, Barradas S, Singer S, Zenger M, Hinz A. Health related quality of life in Colombia: Reference values of the EORTC QLQ-C30. Eur J Cancer Care 2012; 21: 829-836.

27. Shaik F, Uldrick YS, Esterhuizen T, Mosam A. Health-related quality of life in patients treated with antiretroviral therapy only versus chemotherapy and antiretroviral therapy for HIV-associated Kaposi sarcoma: a randomized control trial. J Glob Oncol 2018; 4: 1-9.

28. Cabrera SG, Arteta Z, Meré J, Cavalleri F. Calidad de vida relacionada a la salud en personas con VIH y factores asociados. Rev Méd Urug 2018; 34: 7-19.

29. Fayers P, Aaronson N, Bjordal K, Groenvold M, Curran D, Bottomley A. EORTC QLQ-C30 Scoring Manual. Third. Brussels: EORTC; 2001.

30. Green SB. How many subjects does it take to do a regression analysis? Multivariate Behav Res 1991; 26: 499-510.

31. Centers for Disease Control and Prevention. HIV Surveillance Report; 2017. Available from http://www.cdc.gov/hiv/library/reports/ hiv-surveillance.html.
32. Varni SE, Miller CT, McCuin T, Solomon SE. Disengagement and engagement coping with HIV/AIDS stigma and psychological wellbeing of people with HIV/AIDS. J Soc Clin Psychol 2012; 31: 123150

33. Yaya I, Djalogue L, Patassi AA, et al. Health-related quality of life among people living with HIV/AIDS in Togo: individuals and contextual effects. BMC Res Notes 2019; 12: 140.

34. Finck C, Barradas S, Zenger M, Hinz A. Quality of life in breast cancer: associations with optimism and social support. Int J Clin Health Psychol 2018; 18: 27-34.

35. Sprangers M, Schwartz C. Integrating response shift into healthrelated quality of life research: a theoretical model. Soc Sci Med 1999; 48: 1507-1515.

36. Dinkel A, Nather C, Jaeger H, et al. Stigmatization in HIV/AIDS: first German adaptation of the HIV-stigma scale (HSS-D)]. Psychother Psychosom Med Psychol 2014; 64: 20-27.

37. Zarei N, Joulaei $H$. The impact of perceived stigma, quality of life, and spiritual beliefs on suicidal ideations among HIV-positive patients. AIDS Res Treat 2018; 2018: 6120127.

38. Liu H, Xu Y, Lin X, Shi J, Chen S. Associations between perceived HIV stigma and quality of life at the dyadic level: the actor-partner interdependence model. PLoS One 2013; 8: e55680.

39. Burclau R, Umlauf A, Luca A, et al. Sex based differences in neurocognitive functioning in HIV infected young adults. AIDS 2018; 32: 217-225.

40. Charles B, Jeyaseelan L, Pandian AK, et al. Association between stigma, depression and quality of life of people living with HIV/ AIDS (PLHA) in South India. A community based cross-sectional study. BMC Public Health 2012; 12: 2-11.

41. Maki P, Rubin L, Springer G, et al. Differences in cognitive function between women and men with HIV. J Acquir Immune Defic Syndr 2018; 79: 101-107. 